\title{
Protein Translocation across the Rough Endoplasmic Reticulum
}

\author{
Elisabet C. Mandon, Steven F. Trueman, and Reid Gilmore \\ Department of Biochemistry and Molecular Pharmacology, University of Massachusetts Medical School, \\ Worcester, Massachusetts 01605-2324 \\ Correspondence: reid.gilmore@umassmed.edu
}

The rough endoplasmic reticulum is a major site of protein biosynthesis in all eukaryotic cells, serving as the entry point for the secretory pathway and as the initial integration site for the majority of cellular integral membrane proteins. The core components of the protein translocation machinery have been identified, and high-resolution structures of the targeting components and the transport channel have been obtained. Research in this area is now focused on obtaining a better understanding of the molecular mechanism of protein translocation and membrane protein integration.

P rotein translocation across the rough endoplasmic reticulum (RER) is an ancient and evolutionarily conserved process that is analogous to protein export across the cytoplasmic membranes of eubacterial and archaebacterial cells both with respect to the mechanism and core components. The RER membrane of eukaryotic cells is contiguous with the nuclear envelope and is morphologically composed of interconnected cisternae and tubules. Electron microscope images of mammalian cells and tissues revealed that the cisternal regions of the cytoplasmic surface of the endoplasmic reticulum are densely studded by membranebound ribosomes (Palade 1955a,b), giving rise to the term "rough ER." The RER-bound ribosomes in en face images are often arranged in spirals or hairpins (Palade 1955a; Christensen and Bourne 1999), indicative of polyribo- somes that are actively engaged in protein translation.

Consistent with this high density of membrane-bound ribosomes, the RER is a major site of protein biosynthesis in eukaryotic cells. The nuclear envelope, the Golgi, lysosome, peroxisome, plasma membrane, and endosomes are biosynthetically derived from the rough ER. The three major groups of proteins that are synthesized by RER-bound ribosomes include secretory proteins, integral membrane proteins destined for ER-derived membranes, and the lumenal-resident proteins of the ER, Golgi, nuclear envelope, and lysosome. For those membranes that are not physically linked to the ER (e.g., the lysosome), integral membrane and lumenal proteins are delivered to their destination by vesicular transport pathways. Bioinformatics analysis of fully sequenced eukaryotic

Editors: Susan Ferro-Novick, Tom A. Rapoport, and Randy Schekman

Additional Perspectives on The Endoplasmic Reticulum available at www.cshperspectives.org

Copyright (C) 2013 Cold Spring Harbor Laboratory Press; all rights reserved; doi: 10.1101/cshperspect.a013342

Cite this article as Cold Spring Harb Perspect Biol 2013;5:a013342 
E.C. Mandon et al.

genomes indicates that roughly $30 \%$ of open reading frames encode integral membrane proteins (Wallin and von Heijne 1998); hence, a major role of the RER is the biosynthesis of membrane proteins. An important class of membrane proteins that are integrated into the RER has single carboxy-terminal TM spans and are known as tail-anchored (TA) membrane proteins. The posttranslational integration pathway for TA proteins has been a subject of several recent reviews (Borgese and Fasana 2011; Shao and Hegde 2011), thus we will not address the TA pathway in this article.

\section{THE SIGNAL HYPOTHESIS}

Biochemical experiments to address the role of membrane-bound ribosomes in secretory protein biosynthesis began in earnest in the 1960s (Redman and Sabatini 1966; Redman et al. 1966). In 1971, Gunter Blobel proposed that secretory protein mRNAs encode a signal that promotes targeting of ribosomes to the RER. The following year, Cesar Milstein and colleagues discovered that a secretory protein (IgG light chain) is synthesized as a higher-molecularweight precursor (Milstein et al. 1972). In a landmark paper formally presenting the signal hypothesis, Blobel and Dobberstein showed that the IgG light chain could be synthesized in vitro, cotranslationally translocated across canine pancreas microsomal membranes, and proteolytically processed into the mature polypeptide (Blobel and Dobberstein 1975). During the next several years, protein sequence analysis showed that secretory proteins are synthesized as precursors that have an amino-terminal hydrophobic signal sequence and a processing site for an RER-localized signal peptidase (von Heijne 1983). The TM spans of integral membrane proteins, which are also hydrophobic, function as signal sequences when located near the amino terminus of membrane proteins (Friedlander and Blobel 1985) or when inserted into a signal sequence-deficient reporter protein (Mize et al. 1986). Thus, ribosomes synthesizing secretory or membrane proteins are targeted to the RER by nonidentical segments of hydrophobic amino acids.

\section{TARGETING OF mRNAS AND TRANSLATING RIBOSOMES TO THE ROUGH ENDOPLASMIC RETICULUM}

Although signal sequences provide a proteinbased address code for the ER, what are the cellular proteins or lipids that decode a sequence composed of a string of hydrophobic amino acids? The identification of the signal recognition particle (SRP) by Walter and Blobel resolved this question (Walter and Blobel 1980). The SRP selectively binds to ribosomes translating mRNAs encoding presecretory proteins (Walter et al. 1981), reduces the protein synthesis elongation rate (Walter and Blobel 1981b), and mediates selective targeting of the ribosome-nascent chain complex (RNC) to the RER (Fig. 1) (Walter and Blobel 1981a).

In mammalian cells, the SRP is composed of six protein subunits and the 7S RNA (Walter and Blobel 1982). An elongated architecture of the SRP was determined by mapping proteinbinding sites onto the folded structure of the 7S RNA (Siegel and Walter 1988; Strub and Walter 1990), and by electron microscopy (Andrews et al. 1987). Of the protein subunits, SRP54 has received the most attention because it contains a methionine-rich domain that binds directly to the signal sequence and to the 7S RNA (Zopf et al. 1990). Cryoelectron microscopy of SRP-ribosome-nascent chain complexes (SRP-RNCs) revealed that SRP54 is positioned near the polypeptide exit site on the large ribosomal subunit, whereas the Alu subdomain of the SRP particle is positioned near the elongation factor-binding site (Halic et al. 2004). Recently, several groups have reported that SRP or the eubacterial homolog Ffh (see below) is recruited to the ribosome before the amino terminus of the protein emerges from the polypeptide exit tunnel (Bornemann et al. 2008; Berndt et al. 2009), thereby increasing the probability that SRP will discriminate between an authentic signal sequence and a nonsignal sequence shortly after the amino terminus of the protein emerges from the large ribosomal subunit. Recognition of the signal sequence by the SRP allows cotranslational delivery of RNCs to the RER. Cotranslational integration may be particularly important 


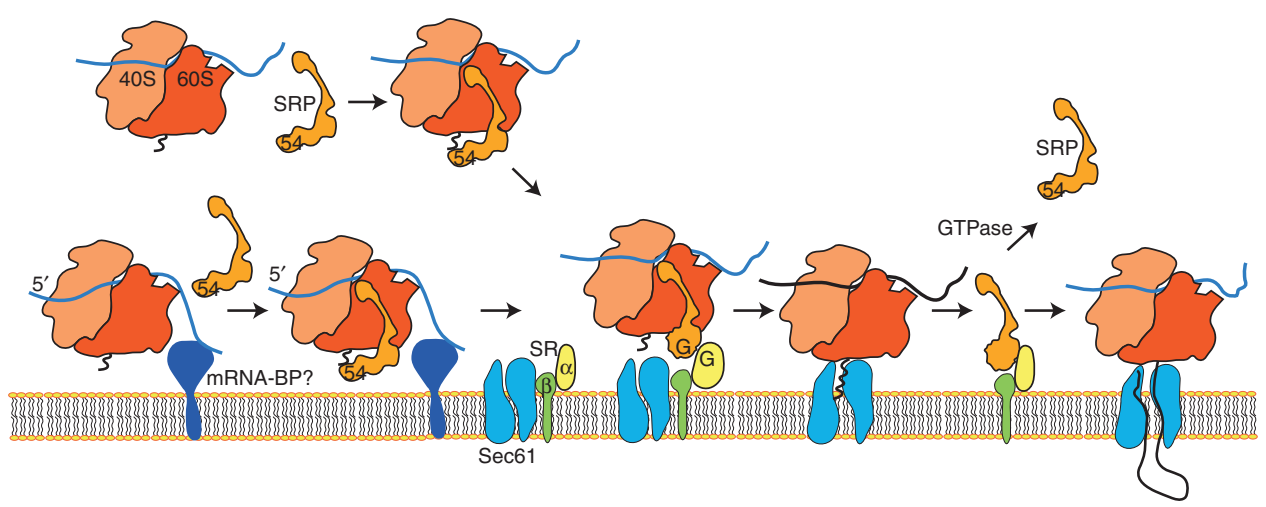

Figure 1. Targeting of RNCs to the Sec61 complex. The mRNAs encoding proteins with ER signal sequences may be targeted to the vicinity of the RER by a translation-independent mechanism and bind to a currently unidentified mRNA-binding protein (mRNA-BP). The SRP particle binds to the $80 \mathrm{~S}$ ribosome and mediates targeting to the ER via interaction with SR $\alpha$. Cooperative GTP binding to SRP54 and SR $\alpha$ leads to dissociation of SRP from the RNC and attachment of the RNC to the Sec61 complex. Signal sequence insertion into the SSB site gates the translocation channel.

for the biosynthesis of multispanning membrane proteins because TM spans are prone to aggregation in aqueous environments.

Are certain classes of mRNAs targeted to the RER by translation-independent pathways? It has long been recognized that membranebound and free polysome fractions isolated from tissues synthesize different classes of proteins (Ramsey and Steele 1976). The use of highthroughput methods to analyze the partitioning of mRNAs between membrane-bound and free polysome fractions showed that nucleocytoplasmic proteins are primarily synthesized by free polysomes and that membrane-bound polysomes are enriched in mRNAs encoding endomembrane resident proteins (Diehn et al. 2000). Unexpectedly, mRNAs encoding certain nucleocytoplasmic proteins (e.g., Hsp90 and calcinuerin) are strongly enriched in the membrane-bound polysome fraction (Diehn et al. 2000; Lerner et al. 2003). Secondly, mRNAs encoding secretory proteins were not as enriched in the membrane-bound polysome fraction as mRNAs encoding endomembrane resident proteins (Chen et al. 2011). Evidence for translation-independent binding of mRNAs to the RER has also been obtained, suggesting that mRNA targeting to the vicinity of the RER may precede SRP-dependent targeting of RNCs to the protein translocation channel (Fig. 1) (Pyhtila et al. 2008).

\section{THE SRP54 AND SR $\alpha$ GTPase REGULATE \\ THE DELIVERY OF RNCs TO THE TRANSLOCATION CHANNEL}

The discovery that SRP delivers RNCs to the RER provided the foundation for identifying an RERlocalized SRP receptor (SR) for the SRP-RNC complex (Gilmore et al. 1982a,b). The heterodimeric SR $(\operatorname{SR} \alpha+\operatorname{SR} \beta)$ is localized to the ER by integration of the $\beta$-subunit (Lauffer et al. 1985). Dissociation of the SRP-SR complex from the signal sequence precedes RNC binding to the protein translocation channel (Gilmore and Blobel 1983).

SR $\alpha$, SRP54, and the 7S RNA are evolutionarily conserved; FtsY and the Ffh-4.5S RNA complex are the eubacterial equivalents of the SR and SRP (Poritz et al. 1988; Poritz et al. 1990; Miller et al. 1994). In the eubacterial organism Escherichia coli, the SRP-SR targeting pathway is primarily involved in the biosynthesis of inner membrane proteins (Ulbrandt et al. 1997; Koch et al. 1999). Most periplasmic proteins and $\beta$ barrel outer membrane proteins are translocated by a posttranslational SecA-SecYEG-dependent pathway (for a recent review, see Park and 
E.C. Mandon et al.

Rapoport 2012). Disruption of the budding yeast (Saccharomyces cerevisiae) genes encoding SR or SRP subunits or the SRP RNA yielded slow-growing strains that have severe, yet transient, defects in protein translocation of a subset of proteins with RER signal sequences (Hann and Walter 1991; Ogg et al. 1992). In contrast to budding yeast, the SRP54 and SRP RNA genes are essential in Schizosaccharomyces pombe (Brennwald et al. 1988; Althoff et al. 1994).

The interaction between the SRP receptor and the SRP-RNC complex is regulated by a GTPase cycle (Connolly and Gilmore 1986, 1989) that results in dissociation of SRP54 from the signal sequence (Connolly et al. 1991) and attachment of the RNC to the protein translocation channel (Fig. 1). Protein sequence analysis and GTPase assays using purified SRP and SR led to the conclusion that $\operatorname{SR} \alpha, \operatorname{SR} \beta$, and SRP54 are members of the GTPase superfamily (Connolly and Gilmore 1993; Miller et al. 1993). The minimal components for the SR-SRP GTPase cycle are SR $\alpha$, SRP54, and the 7S RNA (Miller et al. 1993). The most thorough kinetic analysis of the SRP-SR GTPase cycle has been achieved using bacterially expressed derivatives of Ffh, FtsY, and 4.5S RNA (Peluso et al. 2000; Shan and Walter 2003).

Unlike many GTPases, the hydrolysis cycle of the SRP-SR complex is not regulated by conventional guanine-nucleotide exchange factors (GEFs) or GTPase-activating proteins (GAPs). The requirement for the SRP RNA in the GTPase cycle is explained by the finding that the $4.5 \mathrm{~S}$ RNA increases the rate of Ffh-FtsY complex formation and disassembly following hydrolysis (Peluso et al. 2000). The SRP and SR GTPases have a low affinity for guanine ribonucleotides compared with many other GTPases, and a lower affinity for GTP than for GDP (Connolly and Gilmore 1993; Rapiejko and Gilmore 1997). Indeed, before formation of the SRP-SR complex, GTP binding to Ffh and FtsY is reversible, and the binding specificity (GTP vs. ATP) is surprisingly weak for FtsY (Shan and Walter 2003). GTP hydrolysis by SRP and SR are catalytically linked and dependent on nucleotide occupancy of both sites (Powers and Walter 1995; Rapiejko and Gilmore 1997).
Several roles have been proposed for the SRP-SR GTPase cycle. One role is to control the assembly and disassembly of the SRP-SR complex; nonhydrolyzable GTP analogs stabilize the SRP-SR complex, whereas GTP hydrolysis promotes complex dissociation (Fig. 1) (Connolly et al. 1991). Recent evidence indicates that additional proofreading steps occur after signal sequence recognition by SRP to increase the fidelity of the protein translocation reaction (Zhang et al. 2010). When reconstituted into proteoliposomes, signal sequence dissociation from SRP54 and GTP hydrolysis by the SRPSR complex is blocked unless an active Sec61 complex is present to serve as a receptor for the RNC complex (Song et al. 2000). Thus, the GTPase cycle regulates multiple steps in the delivery of an RNC to the protein translocation channel.

\section{STRUCTURAL BIOLOGY OF THE SRP-SR TARGETING PATHWAY}

SRP54 and Ffh are composed of an amino-terminal domain (N-domain), the central GTPase (G-domain), and the carboxy-terminal methionine-rich M-domain (Bernstein et al. 1989). Homologous N- and G-domains are also present in SR $\alpha$ and FtsY. The simpler composition of the eubacterial SR and SRP facilitated structural analysis of the SRP family of GTPases. High-resolution structures of the nucleotidefree forms of $\mathrm{Ffh}_{\mathrm{NG}}$ and $\mathrm{FtsY}_{\mathrm{NG}}$ (Freymann et al. 1997; Montoya et al. 1997) and the GDP$\mathrm{Mg}^{2+}$-bound form of $\mathrm{Ffh}_{\mathrm{NG}}$ (Freymann et al. 1999) highlighted the homologous architecture of these GTPases and helped explain their low affinity for ribonucleotides. The structure of the $\mathrm{Ffh}_{\mathrm{NG}}-\mathrm{FtsY}_{\mathrm{NG}}$ complex obtained in the presence of a nonhydrolyzable GTP analog revealed a composite active site formed upon heterodimerization (Egea et al. 2004; Focia et al. 2004) that helped explain why Ffh and FtsY act as reciprocal GAPS (Powers and Walter 1995). A cocrystal structure of $\mathrm{Ffh}_{\mathrm{NGM}}$ bound to domain IV of the 4.5S RNA revealed that the hydrophobic signal sequence-binding groove in the M-domain of Ffh terminates at the RNA-binding interface (Batey et al. 2000) and suggests that signal 
sequence binding to the M-domain may be communicated directly to the G-domain via the 4.5S RNA (Rosendal et al. 2003).

\section{TRANSLOCATION CHANNELS AND RIBOSOME-BINDING SITES}

After the discovery of SRP and the SR, several laboratories focused their efforts on the identification of the protein translocation channel. A yeast screen for gene products that were required for translocation of a secretory protein led to the identification of the essential SEC61, SEC62, and SEC63 genes (Deshaies and Schekman 1987; Rothblatt et al. 1989). Subsequent analysis showed that all three genes encode ER-localized integral membrane proteins that assemble into the SEC complex (Deshaies and Schekman 1989; Deshaies et al. 1991; Feldheim et al. 1992). Mutations in Sec61p inhibited translocation of secreted proteins and integration of membrane proteins, thereby providing the first evidence that Sec61 was the core subunit of the protein translocation channel (Stirling et al. 1992).

The mammalian translocation channel was initially detected by cross-linking an in vitroassembled translocation intermediate to several different ER membrane proteins in the 30- to 40-kDa range (Wiedmann et al. 1989; Kellaris et al. 1991). Purification of the cross-linking targets resulted in identification of the TRAM protein (Görlich et al. 1992a) and the Sec61 $\alpha$ protein (Görlich et al. 1992b). Mammalian Sec61 $\alpha$ is homologous to yeast Sec61 and to the E. coli SecY protein (Görlich et al. 1992b), showing that protein translocation channels are conserved between eukaryotic and eubacterial organisms. Fungal genomes (e.g., S. cerevisiae) do not encode an obvious TRAM homolog.

Proteoliposomes containing the mammalian Sec61 complex $(\operatorname{Sec} 61 \alpha$, Sec61 $\beta$, and Sec61 $\gamma)$ and the SR are active in translocation of a subset of secretory proteins (Görlich and Rapoport 1993). Incorporation of TRAM into Sec61SR proteoliposomes stimulates translocation of all substrates tested, consistent with an accessory role for TRAM at an early stage in protein translocation (Voigt et al. 1996). Unlike TRAM, which contacts only the amino-terminal regions of nascent secretory proteins, Sec61 can be cross-linked to a photoreactive amino acid analog incorporated at any site in the nascent polypeptide (Mothes et al. 1994). Thus, Sec61 forms the aqueous transport pore that had been detected by a variety of biophysical and biochemical approaches (Gilmore and Blobel 1985; Simon and Blobel 1991; Crowley et al. 1993,1994).

Long before the identification of Sec61, multiple proteins had been proposed to be ER-localized ribosome receptors. The Sec61 complex binds nontranslating ribosomes with an affinity comparable to ribosome-stripped ER membranes (Kalies et al. 1994). Proteolytic digestion of canine Sec61 in intact membranes inhibits ribosome-binding activity by severing the carboxyl terminus and two cytosolically exposed loops (L6 and L8) (Fig. 2B) (Raden et al. 2000). Charge reversal substitutions at conserved basic residues in L6 (e.g., R275E) and L8 (R406E) of $S$. cerevisiae Sec61p cause a cotranslational translocation defect by interfering with RNC attachment to Sec61 (Cheng et al. 2005).

\section{TRANSFER OF RNCS FROM THE SRP-SR COMPLEX TO THE SEC61 COMPLEX}

The ability of SRP to reduce the protein synthesis elongation rate is necessary in vivo both in budding yeast and in mammalian cells (Mason et al. 2000; Lakkaraju et al. 2008) to allow sufficient time for targeting of SRP-RNC to the SR. In addition to binding SRP54, SR $\alpha$ has a high affinity for the large ribosomal subunit, thereby facilitating formation of the SR-SRP-RNC complex (Mandon et al. 2003). Cryo-EM structures of the SRP-RNC complex and the Sec61RNC complex have shown that the SRP and Sec61 have overlapping binding sites near the polypeptide exit tunnel (Halic et al. 2004). Upon formation of the SR-SRP-RNC complex, movement of the M-domain of SRP54 exposes the Sec61-binding site (Halic et al. 2004) for subsequent attachment of the RNC to the Sec61 complex.

The GTP-bound conformation of SR $\beta$ forms the membrane-binding site for $\mathrm{SR} \alpha$ (Ogg et al. 1998; Legate et al. 2000; Schwartz and Blobel 
E.C. Mandon et al.
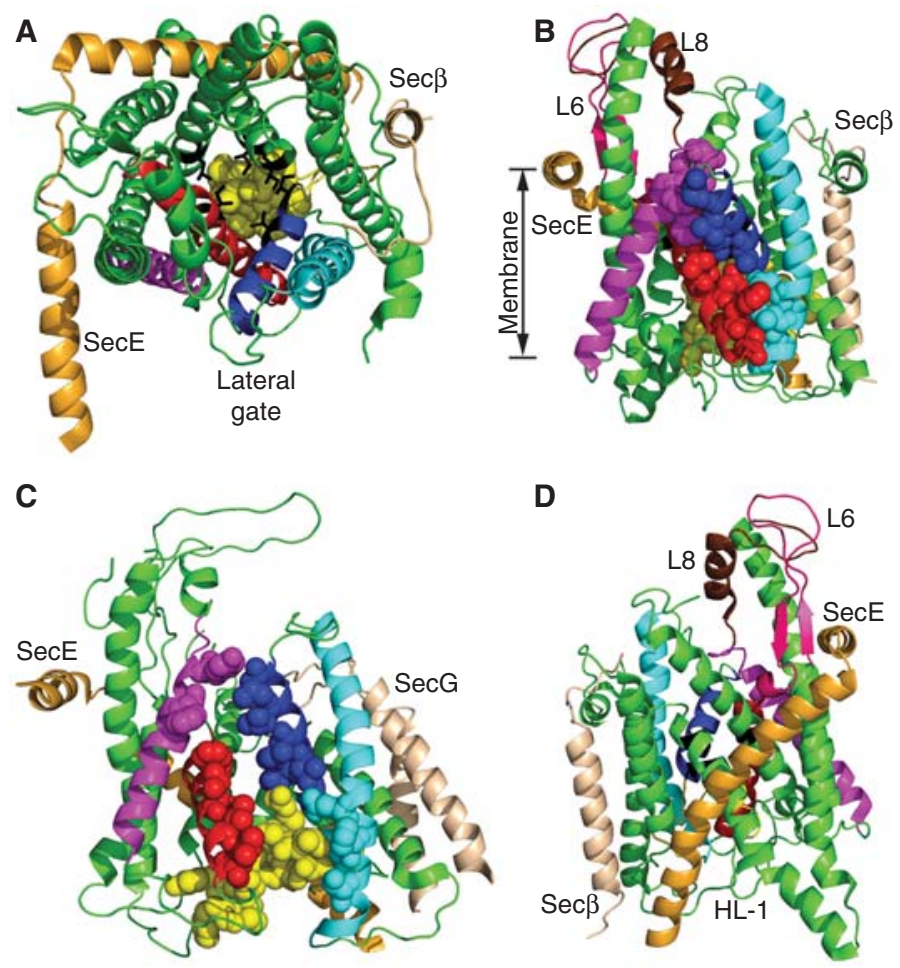

Figure 2. SecYE $\beta$ and SecYEG translocation channels. TM spans of SecYare color coded as follows: TMs 1, 4-6, 9-10 (green), TM2 (blue), TM3 (cyan), TM7 (red), and TM8 (magenta). (Yellow spheres) The plug domain. Cytosolic loops 6 and 8 are pink and chocolate, respectively, in panels $B$ and $D$. ( $A$ ) The cytosolic face of the Methanocaldococcus jannaschii SecYE $\beta$ complex in the closed conformation. (Black sticks) Pore ring residues. (B) Lateral gate of M. jannaschii SecYE $\beta$ viewed from the plane of the membrane. (Spheres) Lateral gate contact residues (LGCRs). (C) The partially open conformation of the Thermotoga maritima SecYEG complex. $(D)$ The hinge domain of $M$. jannaschii SecYE $\beta$. The HL-1 hinge loop is labeled. All structure views were generated using PyMOL and PDB files 1 RHZ and 3DIN.

2003). Interestingly, deletion of the SR $\beta$-TM span has a less severe impact on SR function than inactivation of the SR $\beta$ GTP-binding site (Ogg et al. 1998). Yeast genetic experiments using SR $\beta-\Delta T M$ cells provided evidence that the SR interacts with translocation channels via Sec61 $\beta$ subunits (Jiang et al. 2008), thereby providing a mechanism to position the SRPRNC adjacent to a vacant protein translocation channel (Fig. 1).

\section{STRUCTURES OF PROTEIN TRANSLOCATION CHANNELS}

The first cryo-EM structures of the yeast Sec61RNC complex (Beckmann et al. 1997, 2001) and the mammalian Sec61-80S complex (Hanein et al. 1996; Menetret et al. 2000; Morgan et al. 2002) were thought to contain three to four Sec61 heterotrimers. An oligomeric interface was proposed to form a large-diameter $(\sim 25$ Å) transport pore (Hanein et al. 1996; Beckmann et al. 1997; Morgan et al. 2002). Biophysical studies supported the concept of a large pore ( $\sim 40 \AA$ ) (Hamman et al. 1997) that was sealed by the ribosome on the cytoplasmic face of the ER and by BiP in the ER lumen (Hamman et al. 1998).

The X-ray crystal structure of Methanocaldococcus jannaschii SecYE $\beta$ (Van den Berg et al. 2004) was obtained in the absence of a ribosome or a nascent polypeptide, hence the structure 
is in a closed conformation. The membrane-exposed surface of SecYE $\beta$ complex lacks polar residues, arguing strongly against a transport pore formed by oligomer formation. SecE and $\operatorname{Sec} \beta$, like their eukaryotic homologs Sec61 $\beta$ and Sec61 $\gamma$, are C-tail-anchored membrane proteins with a single TM span (Fig. 2A). The $10 \mathrm{TM}$ spans of SecYare arranged in two five-helix bundles (TM1-5 and TM6-10) to form an hourglassshaped channel with a polar interior (Fig. 2A). A central constriction or pore ring is formed by side chains of hydrophobic residues projecting from TM spans closest to the channel center (Fig. $2 \mathrm{~A}$, side chains shown as black sticks). The exoplasmic face of the channel is blocked by a reentrant loop referred to as the plug domain (Fig. $2 \mathrm{~A}$, yellow spheres). Most point mutations in E. coli SecYEG that cause the prl phenotype, which corresponds to enhanced translocation of precursors with signal sequence mutations, map to the plug domain or the pore ring (Smith et al. 2005). Disulfides formed between a secretory protein precursor and a cysteine residue located near the pore ring provide evidence that secretory proteins are transported through the central pore (Cannon et al. 2005).

Budding yeast express an auxiliary protein translocation channel known as the Ssh1 complex (Finke et al. 1996) that is exclusively involved in the cotranslational translocation pathway (Wittke et al.2002). Higher-resolution cryoEM structures showed that single copies of mammalian Sec61, yeast Ssh1, or E. coli SecYEG form protein-conducting channels when bound to an RNC (Becker et al. 2009) or a 70S ribosome (Menetret et al. 2007). The two primary contact sites on the cytoplasmic surface of Sec61 or Ssh1 for the RNC are loops 6 and 8 (Becker et al. 2009), consistent with previous mutagenesis experiments (Cheng and Gilmore 2006). Cytosolic loop 8 undergoes a conformational change upon RNC binding to project into the polypeptide exit tunnel of the large ribosomal subunit.

TM2 and TM7 (blue and red $\alpha$-helices in Fig. 2) of yeast Sec61 can be photocross-linked to the signal sequence of a nascent polypeptide (Plath et al. 1998), so this region has been termed the signal sequence-binding (SSB) site. Integration of a membrane protein necessitates lateral passage of the TM span from the central pore of SecY or Sec61 into the lipid bilayer. The lateral gate (TM2, TM3, TM7, and TM8) (Fig. 2A,B) is the only site where a TM span could exit the channel interior without crossing a cytosolic or lumenal loop joining two SecY TM spans (Fig. 2A,B).

The Thermatoga maritima SecYEG-SecA complex (Zimmer et al. 2008), the Thermus thermophilus SecYE-Fab complex (Tsukazaki et al. 2008 ), and the Pyrococcus furiosus SecYE $\beta$ complex (Egea and Stroud 2010) provided highresolution structures of partially open protein conducting channels. SecA-dependent opening of SecYEG occurs by rigid-body movement of TMs 6-10 relative to TMs $1-5$ (Zimmer et al. 2008 ) and is accompanied by movement of the plug domain away from the pore ring (Fig. 2C). In the fully open conformation, a translocation channel could accommodate a signal sequence in the SSB site and a nascent polypeptide in the central pore. The segment labeled HL-1 in loop 5 (Fig. 2D) is thought to be a hinge that allows the channel to open (Gumbart and Schulten 2007). Interestingly, the yeast sec61-2 point mutations map to a conserved glycine in HL-1 (Nishikawa et al. 2001), highlighting the importance of the hinge in Sec61 function. Several yeast $\sec 61$ alleles, including $\sec 61-3$, that cause a general defect in protein translocation can be suppressed by prl alleles, indicating that the transition between the closed and open conformations of the channel controls translocation efficiency and fidelity (Trueman et al. 2011).

How is the membrane permeability seal maintained when a translocation channel is in the open or closed conformation? Biophysical studies have suggested that BiP seals the lumenal face of the translocon during membrane protein integration (Hamman et al. 1998; Haigh and Johnson 2002). A second hypothesis was that the plug domain of SecY forms the membrane permeability seal (Van den Berg et al. 2004). Deletion of the plug domain in yeast Sec61p (Junne et al. 2006) or in E. coli SecY (Maillard et al. 2007) causes a minor growth defect and the prl phenotype (Junne et al. 2007). The membrane permeability barrier is reduced in E. coli cells expressing a SecY plug-deletion 
E.C. Mandon et al.

mutant (Saparov et al. 2007; Park and Rapoport 2011) when the channel is in the closed state (Park and Rapoport 2011). Replacement of three or more pore ring residues in E. coli SecYEG with alanine or glycine residues caused a disruption of the membrane permeability seal and a severe growth defect (Park and Rapoport 2011). In contrast, replacement of all six pore residues in yeast Sec61p with alanine or glycine yields viable strains that display the prl phenotype (Junne et al. 2010).

\section{POSTTRANSLATIONAL TRANSLOCATION- ROLE OF THE SEC62/SEC63 COMPLEX}

Translocation assays conducted using microsomes and translation extracts prepared from budding yeast provided overwhelming evidence for an ATP-dependent posttranslational translocation pathway (Hansen et al. 1986; Rothblatt and Meyer 1986; Waters and Blobel 1986). ATP dependence is explained by the involvement of cytoplasmic (Chirico et al. 1988) and lumenal (Vogel et al. 1990) Hsc70 proteins. The Ssa family of cytosolic Hsc70s help maintain precursor proteins in a translocation-competent conformation (Deshaies et al. 1988).

Partitioning of yeast translocation substrates between the cotranslational and posttranslation- al translocation pathways is dependent on the hydrophobicity of the signal sequence ( $\mathrm{Ng}$ et al. 1996). Most integral membrane proteins that lack cleavable signal sequences use the SRP-dependent pathway. Proteins with less hydrophobic cleavable signal sequences are translocated by the SEC complex. The heptameric SEC complex is composed of a heterotrimeric Sec61 complex (Sec61p, Sbh1p, and Sss1p) combined with a Sec62/Sec63 complex (Sec62p, Sec63p, Sec66p, and Sec72p) (Esnault et al. 1993,1994; Feldheim et al. 1993; Fang and Green 1994; Feldheim and Schekman 1994; Panzner et al. 1995). Mutations in yeast BiP (Kar2p), Sec62p, and Sec63p inhibit posttranslational translocation in vivo (Rothblatt et al. 1989) and in vitro (Deshaies and Schekman 1989; Sanders et al. 1992; Brodsky et al. 1995).

The Sec62/Sec63 complex has functionally important cytoplasmic and lumenal domains (Fig. 3A). A point mutation in the sec63-1 allele (Rothblatt et al. 1989) alters a critical residue in the lumenal J-domain of Sec63, thereby inhibiting the interaction between Sec63p and Kar2p (Lyman and Schekman 1995). Binding of Kar2 to the precursor provides a driving force for posttranslational translocation (Matlack et al. 1999). Truncation of a carboxy-terminal 27-residue acidic segment of Sec63p, which interacts
A

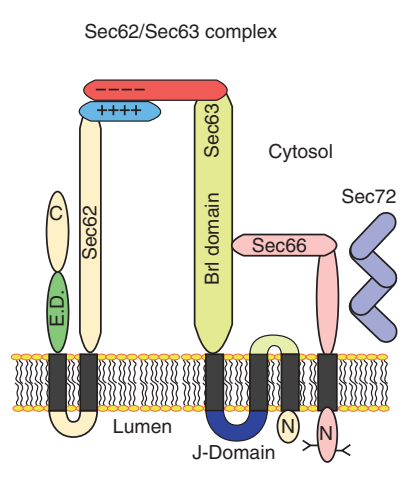

B
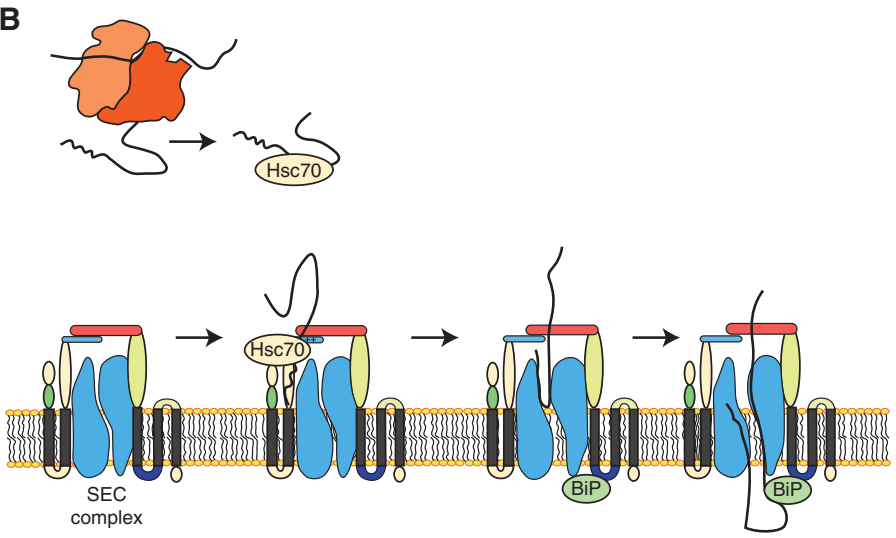

Figure 3. Posttranslational translocation pathway in yeast. (A) A diagram of the yeast Sec62/Sec63 complex. (B) Posttranslational translocation through the SEC complex. Fungi-specific subunits (Sec66 and Sec71) are not shown for clarity. Substrate delivery to the Sec62/Sec63 complex by Hsc70 precedes signal sequence insertion into the SSB site. BiP is recruited to the SEC complex by the lumenal J-domain of Sec63. BiP binding to substrates promotes posttranslational translocation. 
with the basic amino terminus of Sec62 (Fig. 3A) (Wittke et al. 2000), promotes dissociation of Sec62p (Ng and Walter 1996) and causes a translocation defect ( $\mathrm{Ng}$ et al. 1996). Carboxy-terminal deletions of Sec62 that remove a poorly understood effecter domain (Fig. 3B, segment labeled E.D.) are lethal (Wittke et al. 2000).

Photocross-linking experiments have shown that the signal sequence of a secretory protein can be inserted into the SSB site of Sec61 in the absence of ATP. The mature region of the precursor is then in contact with Sec62 (Müsch et al. 1992; Plath et al. 1998). Subsequent transport of the mature region of the protein through the Sec61 is ATP and Kar2p dependent. It is not known whether the Sec62/Sec63 complex simply serves as a targeting site for posttranslational substrates or, instead, promotes lateral gate separation of Sec61 to allow signal sequence insertion into the SSB site.

\section{POTENTIAL ROLES FOR THE SEC62/SEC63 COMPLEX IN COTRANSLATIONAL TRANSLOCATION}

Fully assembled SEC complexes as well as Sec61 heterotrimers are readily detected upon solubilization of yeast microsomes (Panzner et al. 1995). SEC complexes lack ribosome-binding activity (Prinz et al. 2000), suggesting that the cytosolic domains of the Sec62/Sec63 complex occlude the RNC-binding site on Sec61p (Harada et al. 2011). According to one viewpoint, Sec61 and Ssh1 heterotrimers mediate cotranslational translocation (Panzner et al. 1995; Cheng et al. 2005). An alternative hypothesis is that the Sec61 complex is assembled into either the heptameric SEC complex or a hexameric SEC' complex (SEC complexes lacking Sec62) (Jermy et al. 2006). Formation of both the SEC and SEC' complexes is proposed to depend on an interaction between the BRL domain of Sec63 (Jermy et al. 2006) and cytosolic loops of Sec61 (Fig. 3A) (Harada et al. 2011). The role of the Sec62/Sec63 complex in cotranslational integration of membrane proteins has not been resolved, despite an intriguing report that yeast Sec66 and Sec72 are involved (Green et al. 1992). Evidence has been presented that Sec63p (in cooperation with Kar2p) provides an essential driving force for all protein translocation reactions in yeast (Young et al. 2001; Willer et al. 2003; Jermy et al. 2006).

Homologs of Sec62 and Sec63 are encoded by the genomes of metazoan organisms, unlike Sec66 and Sec72, which are fungi-specific. Mammalian Sec62 and Sec63 are abundant ER proteins; biochemical experiments indicate that a portion of the ER pool of Sec62 and Sec63 will copurify with the Sec61 complex (Meyer et al. 2000; Tyedmers et al. 2000; Guth et al. 2004). The physiological role of mammalian Sec62 and Sec63 is unclear because protein translocation primarily occurs by a cotranslational pathway in mammalian cells. Evidence that the mammalian Sec62/Sec63 complex is dispensable for cotranslational translocation of several standard secretory proteins has been provided by in vitro translocation assays using SR-Sec61 proteoliposomes supplemented with the TRAM or TRAP complexes (Görlich and Rapoport 1993; Voigt et al. 1996; Hegde et al. 1998; Fons et al. 2003).

Small secretory proteins (less than 75 residues) are translocated by a posttranslational pathway in mammalian cells (Muller and Zimmermann 1987; Schlenstedt and Zimmermann 1987; Shao and Hegde 2012). Mammalian cells treated with siRNAs specific for Sec62 or Sec63 show reduced translocation or integration of several proteins including preprocecropin $\mathrm{A}$, a small secretory protein (Lang et al. 2012). Thus, one documented role for mammalian Sec62 and Sec63 is posttranslational translocation of proteins that are too small to be targeted by the SRP pathway.

\section{CONCLUDING REMARKS}

Mid- to high-resolution structures of most of the core components of the protein translocation machinery have now been obtained both in isolation and as part of larger complexes. A noteworthy exception is the lack of midto high-resolution structural information regarding the SEC complex. Although we have a reasonable understanding of secretory protein translocation, there remain important knowledge gaps in terms of molecular mechanism. 
E.C. Mandon et al.

The targeting mechanism for small secretory and membrane proteins is not well understood, nor is it known whether small integral membrane proteins are integrated by the Sec61 complex or by the SEC complex. The mechanism of integration of multispanning membrane proteins, because of its greater complexity, is an area of considerable interest. Interactions between the Sec61-RNC complex and adjacent membrane-embedded proteins like TRAM, TRAP, the signal peptidase, and the oligosaccharyltransferase have been detected and are likely to be important. These larger assemblies are often referred to as translocons to reflect the coordination and temporal links between protein translocation, nascent chain modification, and protein folding.

\section{ACKNOWLEDGMENTS}

Research in R.G.'s laboratory is supported by grants from the National Institutes of Health.

\section{REFERENCES}

Althoff SM, Stevens SW, Wise JA. 1994. The SRP54 GTPase is essential for protein export in the fission yeast Schizosaccharomyces pombe. Mol Cell Biol 14: 7839-7854.

Andrews D, Walter P, Ottensmeyer FP. 1987. Evidence for an extended 7SL RNA structure in the signal recognition particle. EMBO J 6: 3471-3477.

Batey RT, Rambo RP, Lucast L, Rha B, Doudna JA. 2000. Crystal structure of the ribonucleoprotein core of the signal recognition particle. Science 287: 1232-1239.

Becker T, Bhushan S, Jarasch A, Armache JP, Funes S, Jossinet F, Gumbart J, Mielke T, Berninghausen O, Schulten K, et al. 2009. Structure of monomeric yeast and mammalian Sec61 complexes interacting with the translating ribosome. Science 326: 1369-1373.

Beckmann R, Bubeck D, Grassucci R, Penczek P, Verschoor A, Blobel G, Frank J. 1997. Alignment of conduits for the nascent polypeptide chain in the ribosome-Sec61 complex. Science 278: 2123-2126.

Beckmann R, Spahn CM, Eswar N, Helmers J, Penczek PA, Sali A, Frank J, Blobel G. 2001. Architecture of the protein-conducting channel associated with the translating 80S ribosome. Cell 107: 361-372.

Berndt U, Oellerer S, Zhang Y, Johnson AE, Rospert S. 2009. A signal-anchor sequence stimulates signal recognition particle binding to ribosomes from inside the exit tunnel. Proc Natl Acad Sci 106: 1398-1403.

Bernstein HD, Poritz MA, Strub K, Hoben PJ, Brenner S, Walter P. 1989. Model for signal sequence recognition from amino-acid sequence of $54 \mathrm{~K}$ subunit of signal recognition particle. Nature 340: 482-486.
Blobel G, Dobberstein B. 1975. Transfer of proteins across membranes. I. Presence of proteolytic processed and unprocessed nascent immunoglobulin light chains on membrane bound ribosomes of murine myeloma. J Cell Biol 67: 835-851.

Borgese N, Fasana E. 2011. Targeting pathways of C-tailanchored proteins. Biochim Biophys Acta 1808: 937-946.

Bornemann T, Jockel J, Rodnina MV, Wintermeyer W. 2008. Signal sequence-independent membrane targeting of ribosomes containing short nascent peptides within the exit tunnel. Nat Struct Mol Biol 15: 494-499.

Brennwald P, Liao X, Holm K, Porter G, Wise JA. 1988. Identification of an essential Schizosaccharomyces pombe RNA homologous to the 7SL component of signal recognition particle. Mol Cell Biol 8: 1580-1590.

Brodsky JL, Goeckeler J, Schekman R. 1995. BiP and Sec63p are required for both co- and posttranslational protein translocation into the yeast endoplasmic reticulum. Proc Natl Acad Sci 92: 9643-9646.

Cannon KS, Or E, Clemons WM Jr, Shibata Y, Rapoport TA. 2005. Disulfide bridge formation between SecY and a translocating polypeptide localizes the translocation pore to the center of SecY. J Cell Biol 169: 219-225.

Chen Q, Jagannathan S, Reid DW, Zheng T, Nicchitta CV. 2011. Hierarchical regulation of mRNA partitioning between the cytoplasm and the endoplasmic reticulum of mammalian cells. Mol Biol Cell 22: 2646-2658.

Cheng Z, Gilmore R. 2006. Slow translocon gating causes cytosolic exposure of transmembrane and lumenal domains during membrane protein integration. Nat Struct Mol Biol 13: 930-936.

Cheng Z, Jiang Y, Mandon EC, Gilmore R. 2005. Identification of cytoplasmic residues of Sec61p involved in ribosome binding and cotranslational translocation. J Cell Biol 168: 67-77.

Chirico WJ, Waters MG, Blobel G. 1988. 70K heat shock related proteins stimulate protein translocation into microsomes. Nature 322: 805-810.

Christensen AK, Bourne CM. 1999. Shape of large bound polysomes in cultured fibroblasts and thyroid epithelial cells. Anat Rec 255: 116-129.

Connolly T, Gilmore R. 1986. Formation of a functional ribosome-membrane junction during translocation requires the participation of a GTP-binding protein. J Cell Biol 103: 2253-2261.

Connolly T, Gilmore R. 1989. The signal recognition particle receptor mediates the GTP-dependent displacement of SRP from the signal sequence of the nascent polypeptide. Cell 57: 599-610.

Connolly T, Gilmore R. 1993. GTP hydrolysis by complexes of the signal recognition particle and the signal recognition particle receptor. J Cell Biol 123: 799-807.

Connolly T, Rapiejko PJ, Gilmore R. 1991. Requirement of GTP hydrolysis for dissociation of the signal recognition particle from its receptor. Science 252: 1171-1173.

Crowley KS, Reinhart GD, Johnson AE. 1993. The signal sequence moves through a ribosomal tunnel into a noncytoplasmic aqueous environment at the ER membrane early in translocation. Cell 73: 1101-1115. 
Crowley KS, Liao S, Worrell VE, Reinhart GD, Johnson AE. 1994. Secretory proteins move through the endoplasmic reticulum via an aqueous, gated pore. Cell 78: 461-471.

Deshaies RJ, Schekman R. 1987. A yeast mutant defective at an early stage in import of secretory protein precursors into the endoplasmic reticulum. J Cell Biol 105: 633-645.

Deshaies RJ, Schekman R. 1989. Sec62 encodes a putative membrane protein required for protein translocation into the yeast endoplasmic reticulum. J Cell Biol 109: 2653-2664.

Deshaies RJ, Koch BD, Werner-Washburne M, Craig EA, Schekman R. 1988. A subfamily of stress proteins facilitates translocation of secretory and mitochondrial precursor polypeptides. Nature 332: 800-805.

Deshaies RJ, Sanders SL, Feldheim DA, Schekman R. 1991. Assembly of yeast Sec proteins involved in translocation into the endoplasmic reticulum into a membrane-bound multisubunit complex. Nature 349: 806-808.

Diehn M, Eisen MB, Botstein D, Brown PO. 2000. Largescale identification of secreted and membrane-associated gene products using DNA microarrays. Nat Genet 25: $58-62$.

Egea PF, Stroud RM. 2010. Lateral opening of a translocon upon entry of protein suggests the mechanism of insertion into membranes. Proc Natl Acad Sci 107: 1718217187.

Egea PF, Shan SO, Napetschnig J, Savage DF, Walter P, Stroud RM. 2004. Substrate twinning activates the signal recognition particle and its receptor. Nature 427: $215-$ 221.

Esnault Y, Blondel M-O, Deshaies R, Schekman R, Képes F 1993. The yeast SSS1 gene is essential for secretory protein translocation and encodes a conserved protein of the endoplasmic reticulum. EMBO J 12: 4083-4093.

Esnault Y, Feldheim D, Blondel M-O, Schekman R, Képes F. 1994. SSS1 encodes a stabilizing component of the Sec6 subcomplex of the yeast protein translocation apparatus. J Biol Chem 269: 27478-27485.

Fang H, Green N. 1994. Nonlethal sec71-1 and sec72-1 mutations eliminate proteins associated with the Sec63pBiP complex from S. cerevisiae. Mol Biol Cell 5: 933-942.

Feldheim D, Schekman R. 1994. Sec72p contributes to the selective recognition of signal peptides by the secretory polypeptide translocation complex. J Cell Biol 126: 935-943.

Feldheim D, Rothblatt J, Schekman R. 1992. Topology and functional domains of Sec63p, an endoplasmic reticulum membrane protein required for secretory protein translocation. Mol Cell Biol 12: 3288-3296.

Feldheim DA, Yoshimura K, Admon A, Schekman R. 1993. Structural and functional characterization of Sec66p, a new subunit of the polypeptide translocation apparatus in yeast endoplasmic reticulum. Mol Biol Cell 4: 931-939.

Finke K, Plath K, Panzer S, Prehn S, Rapoport TA, Hartmann E, Sommer T. 1996. A second trimeric complex containing homologues of the Sec61p complex functions in protein transport across the ER membrane of S. cerevisiae. EMBO J 15: 1482-1494.

Focia PJ, Shepotinovskaya IV, Seidler JA, Freymann DM. 2004. Heterodimeric GTPase core of the SRP targeting complex. Science 303: 373-377.
Fons RD, Bogert BA, Hegde RS. 2003. Substrate-specific function of the translocon-associated protein complex during translocation across the ER membrane. J Cell Biol 160: 529-539.

Freymann DM, Keenan RJ, Stroud RM, Walter P. 1997. Structure of the conserved GTPase domain of the signal recognition particle. Nature 385: 361-364.

Freymann DM, Keenan RJ, Stroud RM, Walter P. 1999. Functional changes in the structure of the SRP GTPase on binding GDP and $\mathrm{Mg}^{2+}$ GDP. Nat Struct Biol 6: 793801.

Friedlander M, Blobel G. 1985. Bovine opsin has more than one signal sequence. Nature 318: $338-343$.

Gilmore R, Blobel G. 1983. Transient involvement of signal recognition particle and its receptor in the microsomal membrane prior to protein translocation. Cell 35: 677-685.

Gilmore R, Blobel G. 1985. Translocation of secretory proteins across the microsomal membrane occurs through an environment accessible to aqueous perturbants. Cell 42: 497-505.

Gilmore R, Blobel G, Walter P. 1982a. Protein translocation across the endoplasmic reticulum. I. Detection in the microsomal membrane of a receptor for the signal recognition particle. J Cell Biol 95: 463-469.

Gilmore R, Walter P, Blobel G. 1982b. Protein translocation across the endoplasmic reticulum. II. Isolation and characterization of the signal recognition particle receptor. J Cell Biol 95: 470-477.

Görlich D, Rapoport TA. 1993. Protein translocation into proteoliposomes reconstituted from purified components of the ER membrane. Cell 75: 615-630.

Görlich D, Hartmann E, Prehn S, Rapoport T. 1992a. A protein of the endoplasmic reticulum involved early in polypeptide translocation. Nature 357: 47-52.

Görlich D, Prehn S, Hartmann E, Kalies K-U, Rapoport TA. 1992b. A mammalian homologue of Sec61p and SecYp is associated with ribosomes and nascent polypeptides during translocation. Cell 71: 489-503.

Green N, Fang H, Walter P. 1992. Mutants in three novel complementation groups inhibit membrane protein insertion into and soluble protein translocation across the endoplasmic reticulum membrane of Saccharomyces cerevisiae. J Cell Biol 116: 597-604.

Gumbart J, Schulten K. 2007. Structural determinants of lateral gate opening in the protein translocon. Biochemistry 46: 11147-11157.

Guth S, Volzing C, Muller A, Jung M, Zimmermann R. 2004. Protein transport into canine pancreatic microsomes: A quantitative approach. Eur J Biochem 271: 3200-3207.

Haigh NG, Johnson AE. 2002. A new role for BiP: Closing the aqueous translocon pore during protein integration into the ER membrane. J Cell Biol 156: 261-270.

Halic M, Becker T, Pool MR, Spahn CM, Grassucci RA, Frank J, Beckmann R. 2004. Structure of the signal recognition particle interacting with the elongation-arrested ribosome. Nature 427: 808-814.

Hamman BD, Chen J-C, Johnson EE, Johnson AE. 1997. The aqueous pore through the translocon has a diameter of $40-60 \AA$ during cotranslational protein translocation at the ER membrane. Cell 89: 535-544. 
E.C. Mandon et al.

Hamman BD, Hendershot LM, Johnson AE. 1998. BiP maintains the permeability barrier of the ER membrane by sealing the lumenal end of the translocation pore before and early in translocation. Cell 92: 747-758.

Hanein D, Matlack KES, Jungnickel B, Plath K, Kalies K-U, Miller KR, Rapoport TA, Akey CW. 1996. Oligomeric rings of the Sec61p complex induced by ligands required for protein translocation. Cell 87: 721-732.

Hann BC, Walter P. 1991. The signal recognition particle in S. cerevisiae. Cell 67: 131-144.

Hansen W, Garcia PD, Walter P. 1986. In vitro protein translocation across the yeast endoplasmic reticulum. ATPdependent posttranslational translocation of the prepro- $\alpha$-factor. Cell 45: 397-406.

Harada Y, Li H, Wall JS, Lennarz WJ. 2011. Structural studies and the assembly of the heptameric post-translational translocon complex. J Biol Chem 286: 2956-2965.

Hegde RS, Voigt S, Rapoport TA, Lingappa VR. 1998. TRAM regulates the exposure of nascent secretory proteins to the cytosol during translocation into the endoplasmic reticulum. Cell 92: 621-631.

Jermy AJ, Willer M, Davis E, Wilkinson BM, Stirling CJ. 2006. The Brl domain in Sec63p is required for assembly of functional endoplasmic reticulum translocons. J Biol Chem 281: 7899-7906.

Jiang Y, Cheng Z, Mandon EC, Gilmore R. 2008. An interaction between the SRP receptor and the translocon is critical during cotranslational protein translocation. J Cell Biol 180: 1149-1161.

Junne T, Schwede T, Goder V, Spiess M. 2006. The plug domain of yeast Sec61p is important for efficient protein translocation, but is not essential for cell viability. Mol Biol Cell 17: 4063-4068.

Junne T, Schwede T, Goder V, Spiess M. 2007. Mutations in the Sec61p channel affecting signal sequence recognition and membrane protein topology. J Biol Chem 282: 33201-33209.

Junne T, Kocik L, Spiess M. 2010. The hydrophobic core of the Sec61 translocon defines the hydrophobicity threshold for membrane integration. Mol Biol Cell 21: $1662-1670$.

Kalies K-U, Görlich D, Rapoport TA. 1994. Binding of ribosomes to the rough endoplasmic reticulum is mediated by the Sec61p-complex. J Cell Biol 126: 925-934.

Kellaris KV, Bowen S, Gilmore R. 1991. ER translocation intermediates are adjacent to a nonglycosylated $34-\mathrm{kD}$ integral membrane protein. J Cell Biol 114: 21-33.

Koch HG, Hengelage T, Neumann-Haefelin C, MacFarlane J, Hoffschulte HK, Schimz KL, Mechler B, Muller M. 1999. In vitro studies with purified components reveal signal recognition particle (SRP) and SecA/ $\mathrm{SecB}$ as constituents of two independent protein-targeting pathways of Escherichia coli. Mol Biol Cell 10: 2163-2173.

Lakkaraju AK, Mary C, Scherrer A, Johnson AE, Strub K. 2008. SRP keeps polypeptides translocation-competent by slowing translation to match limiting ER-targeting sites. Cell 133: 440-451.

Lang S, Benedix J, Fedeles SV, Schorr S, Schirra C, Schauble N, Jalal C, Greiner M, Hassdenteufel S, Tatzelt J, et al. 2012. Different effects of Sec61 $\alpha$, Sec62 and Sec63 depletion on transport of polypeptides into the endoplasmic reticulum of mammalian cells. J Cell Sci 125: $1958-1969$.

Lauffer L, Garcia PD, Harkins RN, Coussens L, Ullrich A, Walter P. 1985. Topology of signal recognition particle receptor in endoplasmic reticulum membrane. Nature 318: $334-338$

Legate KR, Falcone D, Andrews DW. 2000. Nucleotidedependent binding of the GTPase domain of the signal recognition particle receptor $\beta$-subunit to the $\alpha$-subunit. J Biol Chem 275: 27439-27446.

Lerner RS, Seiser RM, Zheng T, Lager PJ, Reedy MC, Keene JD, Nicchitta CV. 2003. Partitioning and translation of mRNAs encoding soluble proteins on membranebound ribosomes. RNA 9: 1123-1137.

Lyman SK, Schekman R. 1995. Interaction between BiP and Sec63 is required for the completion of protein translocation across the ER of Saccharomyces cerevisiae. J Cell Biol 131: 1163-1171.

Maillard AP, Lalani S, Silva F, Belin D, Duong F. 2007. Deregulation of the SecYEG translocation channel upon removal of the plug domain. J Biol Chem 282: 12811287.

Mandon EC, Jiang Y, Gilmore R. 2003. Dual recognition of the ribosome and the signal recognition particle by the SRP receptor during protein targeting to the endoplasmic reticulum. J Cell Biol 162: 575-585.

Mason N, Ciufo LF, Brown JD. 2000. Elongation arrest is a physiologically important function of signal recognition particle. EMBO J 19: 4164-4174.

Matlack KE, Misselwitz B, Plath K, Rapoport TA. 1999. BiP acts as a molecular ratchet during posttranslational transport of prepro- $\alpha$ factor across the ER membrane. Cell 97: 553-564.

Menetret J, Neuhof A, Morgan DG, Plath K, Radermacher M, Rapoport TA, Akey CW. 2000. The structure of ribosome-channel complexes engaged in protein translocation. Mol Cell 6: 1219-1232.

Menetret JF, Schaletzky J, Clemons WM Jr, Osborne AR, Skanland SS, Denison C, Gygi SP, Kirkpatrick DS, Park E, Ludtke SJ, et al. 2007. Ribosome binding of a single copy of the SecY complex: Implications for protein translocation. Mol Cell 28: 1083-1092.

Meyer HA, Grau H, Kraft R, Kostka S, Prehn S, Kalies KU, Hartmann E. 2000. Mammalian Sec61 is associated with Sec62 and Sec63. J Biol Chem 275: 14550-14557.

Miller JD, Wilhelm H, Gierasch L, Gilmore R, Walter P. 1993. GTP binding and hydrolysis by the signal recognition particle during initiation of protein translocation. Nature 366: $351-354$

Miller JD, Bernstein HD, Walter P. 1994. Interaction of E. coli Ffh/4.5S ribonucleoprotein and FtsY mimics that of mammalian signal recognition particle and its receptor. Nature 367: 657-659.

Milstein C, Brownlee GG, Harrison TM, Mathews MB. 1972. A possible precursor of immunoglobulin light chains. Nat New Biol 239: 117-120.

Mize NK, Andrews DW, Lingappa VR. 1986. A stop transfer sequence recognizes receptors for nascent chain translocation across the endoplasmic reticulum. Cell 47: 711-719. 
Montoya G, Svensson C, Luirink J, Sinning I. 1997. Crystal structure of the NG domain from the signal recognition particle receptor FtsY. Nature 385: 365-368.

Morgan DG, Menetret JF, Neuhof A, Rapoport TA, Akey CW. 2002. Structure of the mammalian ribosome-channel complex at $17 \AA$ resolution. J Mol Biol 324: $871-886$

Mothes W, Prehn S, Rapoport TA. 1994. Systematic probing of the environment of a translocating secretory protein during translocation through the ER membrane. EMBOJ 13: 3973-3982.

Muller G, Zimmermann R. 1987. Import of honeybee prepromelittin into the endoplasmic reticulum: Structural basis for independence of SRP and docking protein. EMBO J 6: 2099-2107.

Müsch A, Wiedmann M, Rapoport TA. 1992. Yeast Sec proteins interact with polypeptides traversing the endoplasmic reticulum membrane. Cell 69: 343-352.

Ng DTW, Walter P. 1996. ER membrane protein complex required for nuclear fusion. J Cell Biol 132: 499-509.

Ng DTW, Brown JD, Walter P. 1996. Signal sequences specify the targeting route to the endoplasmic reticulum. J Cell Biol 134: 269-278.

Nishikawa S-I, Fewell SW, Kato Y, Brodsky JL, Endo T. 2001 Molecular chaperones in the yeast endoplasmic reticulum maintain the solubility of proteins for retrotranslocation and degradation. J Cell Biol 153: 1061-1070.

Ogg SC, Poritz MA, Walter P. 1992. Signal recognition particle receptor is important for cell growth and protein secretion in Saccharomyces cerevisiae. Mol Biol Cell 3: 895-911.

Ogg SC, Barz WP, Walter P. 1998. A functional GTPase domain, but not its transmembrane domain, is required for function of the SRP receptor $\beta$-subunit. J Cell Biol 142: 341-354.

Palade GE. 1955a. A small particulate component of the cytoplasm. J Biophys Biochem Cytol 1: 59-68.

Palade GE. 1955b. Studies on the endoplasmic reticulum. II. Simple dispositions in cells in situ. J Biophys Biochem Cytol 1: 567-582.

Panzner S, Dreier L, Hartmann E, Kostka S, Rapoport TA. 1995. Posttranslational protein transport in yeast reconstituted with a purified complex of Sec proteins and Kar2p. Cell 81: 561-570.

Park E, Rapoport TA. 2011. Preserving the membrane barrier for small molecules during bacterial protein translocation. Nature 473: 239-242.

Park E, Rapoport TA. 2012. Mechanisms of Sec61/SecYmediated protein translocation across membranes. Annu Rev Biophys 41: 21-40.

Peluso P, Herschlag D, Nock S, Freymann DM, Johnson AE, Walter P. 2000. Role of 4.5S RNA in assembly of the bacterial signal recognition particle with its receptor. Science 288: 1640-1643.

Plath K, Mothes W, Wilkinson BM, Stirling CJ, Rapoport TA. 1998. Signal sequence recognition in posttranslational protein transport across the yeast ER membrane. Cell 94: 795-807.

Poritz MA, Strub K, Walter P. 1988. Human SRP RNA and E. coli $4.5 S$ RNA contain a highly homologous structural domain. Cell 55: 4-6.
Poritz MA, Bernstein HD, Strub K, Zopf D, Wilhelm H Walter P. 1990. An E. coli ribonucleoprotein containing 4.5S RNA resembles mammalian signal recognition particle. Science 250: 1111-1117.

Powers T, Walter P. 1995. Reciprocal stimulation of GTP hydrolysis by two directly interacting GTPases. Science 269: 1422-1424.

Prinz A, Hartmann E, Kalies KU. 2000. Sec61p is the main ribosome receptor in the endoplasmic reticulum of $\mathrm{Sac}$ charomyces cerevisiae. Biol Chem 381: 1025-1029.

Pyhtila B, Zheng T, Lager PJ, Keene JD, Reedy MC, Nicchitta CV. 2008. Signal sequence- and translation-independent mRNA localization to the endoplasmic reticulum. RNA 14: 445-453.

Raden D, Song W, Gilmore R. 2000. Role of the cytoplasmic segments of Sec61 $\alpha$ in the ribosome-binding and translocation-promoting activities of the Sec61 complex. J Cell Biol 150: 53-64.

Ramsey JC, Steele WJ. 1976. A procedure for the quantitative recovery of homogenous populations of undegraded free and bound polysomes from rat liver. Biochemistry 15: 1704-1712.

Rapiejko PJ, Gilmore R. 1997. Empty site forms of the SRP54 and SR $\alpha$ GTPases mediate targeting of ribosome-nascent chain complexes to the endoplasmic reticulum. Cell 89: 703-713.

Redman C, Sabatini DD. 1966. Vectorial discharge of peptides released by puromycin from attached ribosomes. Proc Natl Acad Sci 56: 608-615.

Redman C, Siekevitz P, Palade GE. 1966. Synthesis and transfer of amylase in pigeon pancreatic microsomes. J Biol Chem 241: 1150-1158.

Rosendal KR, Wild K, Montoya G, Sinning I. 2003. Crystal structure of the complete core of archaeal signal recognition particle and implications for interdomain communication. Proc Natl Acad Sci 100: 14701-14706.

Rothblatt JA, Meyer DI. 1986. Secretion in yeast: Translocation and glycosylation of prepro- $\alpha$-factor in vitro can occur via an ATP-dependent post-translational mechanism. EMBO J 5: 1031-1036.

Rothblatt JA, Deshaies RJ, Sanders SL, Daum G, Schekman R. 1989. Multiple genes are required for proper insertion of secretory proteins into the endoplasmic reticulum in yeast. J Cell Biol 109: 2641-2652.

Sanders SL, Whitfield KM, Vogel JP, Rose MD, Schekman RW. 1992. Sec61p and Bip directly facilitate polypeptide translocation into the ER. Cell 69: 353-365.

Saparov SM, Erlandson K, Cannon K, Schaletzky J, Schulman S, Rapoport TA, Pohl P. 2007. Determining the conductance of the SecY protein translocation channel for small molecules. Mol Cell 26: 501-509.

Schlenstedt G, Zimmermann R. 1987. Import of frog prepropeptide GLa into microsomes requires ATP but does not involve docking protein or ribosomes. $E M B O J \mathbf{6}$ : 699-703.

Schwartz T, Blobel G. 2003. Structural basis for the function of the $\beta$ subunit of the eukaryotic signal recognition particle receptor. Cell 112: 793-803.

Shan SO, Walter P. 2003. Induced nucleotide specificity in a GTPase. Proc Natl Acad Sci 100: 4480-4485. 
E.C. Mandon et al.

Shao S, Hegde RS. 2011. Membrane protein insertion at the endoplasmic reticulum. Annu Rev Cell Dev Biol 27: 2556.

Shao S, Hegde RS. 2012. A calmodulin-dependent translocation pathway for small secretory proteins. Cell 147: 1576-1588.

Siegel V, Walter P. 1988. Binding sites of the 19-kDa and 68/ $72-\mathrm{kDa}$ signal recognition particle (SRP) proteins on SRP RNA as determined by protein-RNA "footprinting." Proc Natl Acad Sci 85: 1801-1805.

Simon SM, Blobel G. 1991. A protein-conducting channel in the endoplasmic reticulum. Cell 65: 371-380.

Smith MA, Clemons WM Jr, DeMars CJ, Flower AM. 2005. Modeling the effects of prl mutations on the Escherichia coli SecY complex. J Bacteriol 187: 6454-6465.

Song W, Raden D, Mandon EC, Gilmore R. 2000. Role of Sec61 $\alpha$ in the regulated transfer of the ribosome-nascent chain complex from the signal recognition particle to the translocation channel. Cell 100: 333-343.

Stirling CJ, Rothblatt J, Hosobuchi M, Deshaies R, Schekman R. 1992. Protein translocation mutants defective in the insertion of integral membrane proteins into the endoplasmic reticulum. Mol Biol Cell 3: 129-142.

Strub K, Walter P. 1990. Assembly of the Alu domain of the signal recognition particle (SRP): Dimerization of the two protein components is required for efficient binding to SRP RNA. Mol Cell Biol 10: 777-784.

Trueman SF, Mandon EC, Gilmore R. 2011. Translocation channel gating kinetics balances protein translocation efficiency with signal sequence recognition fidelity. Mol Biol Cell 22: 2983-2993.

Tsukazaki T, Mori H, Fukai S, Ishitani R, Mori T, Dohmae N, Perederina A, Sugita Y, Vassylyev DG, Ito K, et al. 2008. Conformational transition of Sec machinery inferred from bacterial SecYE structures. Nature 455: 988-991.

Tyedmers J, Lerner M, Bies C, Dudek J, Skowronek MH, Haas IG, Heim N, Nastainczyk W, Volkmer J, Zimmermann R. 2000. Homologs of the yeast Sec complex subunits Sec62p and Sec63p are abundant proteins in dog pancreas microsomes. Proc Natl Acad Sci 97: 7214-7219.

Ulbrandt ND, Newitt JA, Bernstein HD. 1997. The E. coli signal recognition particle is required for the insertion of a subset of inner membrane proteins. Cell 88: 187-196.

Van den Berg B, Clemons WM Jr, Collinson I, Modis Y, Hartmann E, Harrison SC, Rapoport TA. 2004. X-ray structure of a protein-conducting channel. Nature 427: $36-44$.

Vogel JP, Misra LM, Rose MD. 1990. Loss of BiP/GRP78 function blocks translocation of secretory proteins in yeast. J Cell Biol 110: 1885-1895.

Voigt S, Jungnickel B, Hartmann E, Rapoport TA. 1996. Signal sequence-dependent function of the TRAM protein during early phases of protein transport across the endoplasmic reticulum. J Cell Biol 134: 25-35.

von Heijne G. 1983. Patterns of amino acids near signal sequence cleavage sites. Eur J Biochem 133: 17-21.

Wallin E, von Heijne G. 1998. Genome-wide analysis of integral membrane proteins from eubacterial, archaean, and eukaryotic organisms. Protein Sci 7: 1029-1038.
Walter P, Blobel G. 1980. Purification of a membrane-associated protein complex required for protein translocation across the endoplasmic reticulum. Proc Natl Acad Sci 77: 7112-7116.

Walter P, Blobel G. 1981a. Translocation of proteins across the endoplasmic reticulum. II. Signal recognition protein (SRP) mediates the selective binding to microsomal membranes of in-vitro-assembled polysomes synthesizing secretory protein. J Cell Biol 91: 551-556.

Walter P, Blobel G. 1981b. Translocation of proteins across the endoplasmic reticulum. III. Signal recognition protein (SRP) causes signal sequence-dependent and sitespecific arrest of chain elongation that is released by microsomal membranes. J Cell Biol 91: 557-561.

Walter P, Blobel G. 1982. Signal recognition particle contains a 7S RNA essential for protein translocation across the endoplasmic reticulum. Nature 299: 691-698.

Walter P, Ibrahimi I, Blobel G. 1981. Translocation of proteins across the endoplasmic reticulum. I. Signal recognition protein (SRP) binds to in-vitro-assembled polysomes synthesizing secretory protein. J Cell Biol 91: 545-550.

Waters MG, Blobel G. 1986. Secretory protein translocation in a yeast cell-free system can occur posttranslationally and requires ATP hydrolysis. J Cell Biol 102: 1543-1550.

Wiedmann M, Goerlich D, Hartmann E, Kurzchalia TV, Rapoport TA. 1989. Photocrosslinking demonstrates proximity of a $34 \mathrm{kDa}$ membrane protein to different portions of preprolactin during translocation through the endoplasmic reticulum. FEBS Lett 257: 263-268.

Willer M, Jermy AJ, Steel GJ, Garside HJ, Carter S, Stirling CJ. 2003. An in vitro assay using overexpressed yeast SRP demonstrates that cotranslational translocation is dependent upon the J-domain of Sec63p. Biochemistry 42: 7171-7177.

Wittke S, Dunnwald M, Johnsson N. 2000. Sec62p, A component of the endoplasmic reticulum protein translocation machinery, contains multiple binding sites for the sec-complex. Mol Biol Cell 11: 3859-3871.

Wittke S, Dunnwald M, Albertsen M, Johnsson N. 2002. Recognition of a subset of signal sequences by Sshlp, a Sec61p-related protein in the membrane of endoplasmic reticulum of yeast Saccharomyces cerevisiae. Mol Biol Cell 13: 2223-2232.

Young BP, Craven RA, Reid PJ, Willer M, Stirling CJ. 2001. Sec63p and Kar2p are required for the translocation of SRP-dependent precursors into the yeast endoplasmic reticulum in vivo. EMBO J 20: 262-271.

Zhang X, Rashid R, Wang K, Shan SO. 2010. Sequential checkpoints govern substrate selection during cotranslational protein targeting. Science 328: 757-760.

Zimmer J, Nam Y, Rapoport TA. 2008. Structure of a complex of the ATPase SecA and the protein-translocation channel. Nature 455: 936-943.

Zopf D, Bernstein HD, Johnson AE, Walter P. 1990. The methionine-rich domain of the $54 \mathrm{kD}$ protein subunit of the signal recognition particle contains an RNA binding site and can be crosslinked to a signal sequence. EMBO J 9: 4511-4517. 


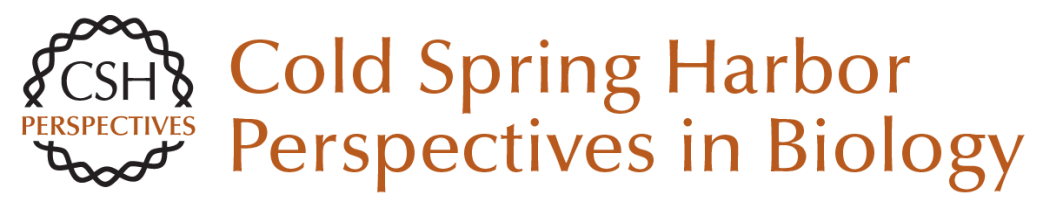

\section{Protein Translocation across the Rough Endoplasmic Reticulum}

Elisabet C. Mandon, Steven F. Trueman and Reid Gilmore

Cold Spring Harb Perspect Biol 2013; doi: 10.1101/cshperspect.a013342 originally published online December 18, 2012

\section{Subject Collection The Endoplasmic Reticulum}

Sorting and Export of Proteins at the Endoplasmic Reticulum Ishier Raote, Sonashree Saxena and Vivek Malhotra

Endoplasmic Reticulum Membrane Contact Sites, Lipid Transport, and Neurodegeneration Andrés Guillén-Samander and Pietro De Camilli

AMPylation and Endoplasmic Reticulum Protein Folding Homeostasis Luke A. Perera and David Ron

The Endoplasmic Reticulum and the Fidelity of Nascent Protein Localization Michael J. McKenna and Sichen Shao

Endoplasmic Reticulum Architecture and Inter-Organelle Communication in Metabolic Health and Disease Ana Paula Arruda and Günes Parlakgül

Regulation and Functions of the ER-Associated Nrf1 Transcription Factor

Gary Ruvkun and Nicolas Lehrbach

Mechanism of Protein Translocation by the Sec61 Translocon Complex Samuel Itskanov and Eunyong Park
Glycerolipid Synthesis and Lipid Droplet Formation in the Endoplasmic Reticulum Robert V. Farese, Jr. and Tobias C. Walther

The Biogenesis of Multipass Membrane Proteins Luka Smalinskaite and Ramanujan S. Hegde

A TAle of Two Pathways: Tail-Anchored Protein Insertion at the Endoplasmic Reticulum Alina Guna, Masami Hazu, Giovani Pinton Tomaleri, et al.

Cholesterol Transport to the Endoplasmic

Reticulum John P. Kennelly and Peter Tontonoz

The Role of the Rhomboid Superfamily in ER

Protein Quality Control: From Mechanisms and Functions to Diseases Satarupa Bhaduri, Nicola A. Scott and Sonya E. Neal

ER-Phagy: Quality and Quantity Control of the Endoplasmic Reticulum by Autophagy Haruka Chino and Noboru Mizushima

Structure and Function of the Nuclear Pore Complex

Stefan Petrovic, George W. Mobbs, Christopher J. Bley, et al.

For additional articles in this collection, see http://cshperspectives.cshlp.org/cgi/collection/

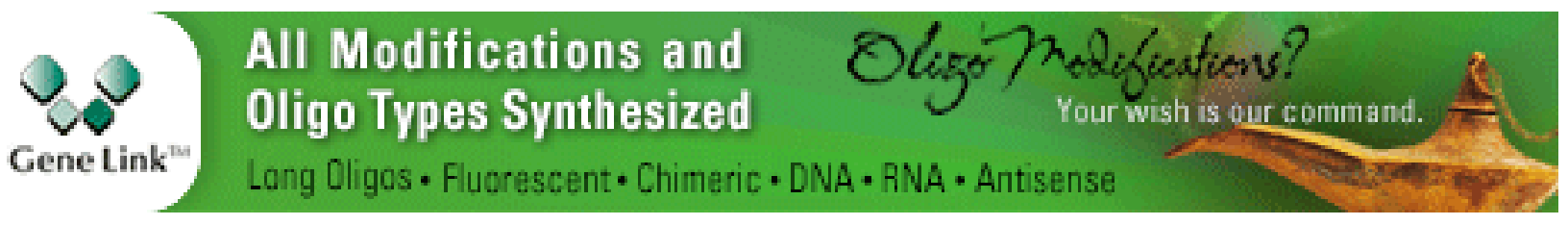




\section{Evolutionary Aspects of the Unfolded Protein Response \\ Kazutoshi Mori}

Post-Translational Regulation of HMG CoA Reductase

Youngah Jo and Russell A. DeBose-Boyd

For additional articles in this collection, see http://cshperspectives.cshlp.org/cgi/collection/

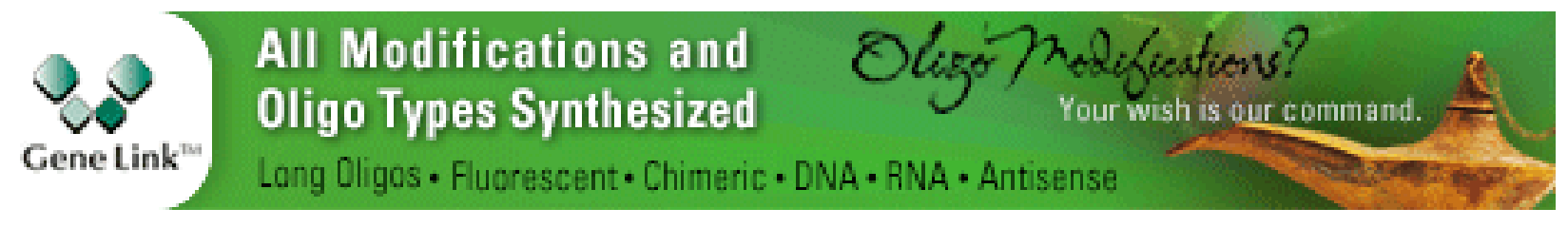

Copyright @ 2013 Cold Spring Harbor Laboratory Press; all rights reserved 